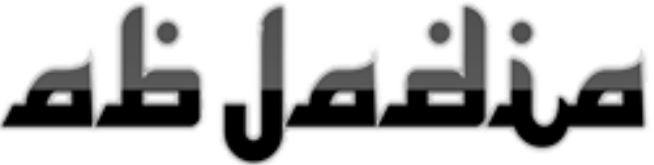 \\ International Journal of Education}

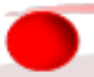

Di Publisher

Fakultas Ilmu Tarbiyah dan Keguruan

Universitas Islam Negeri (UIN)

Mualana Malik Ibrahim Malang

Indonesia

- 2443-0587 - ISSN Online

尚 2528-3979 - ISSN Print

(1) History Article

t) Received : 16-08-2016

(ify) Reviced : 03-09-2016

目 Accepted : 16-12-2016

dx.doi.org/ 10.18860/abj.v1i2.3984

http://ejournal.uin-malang.ac.id/index.php/ abjadia/article/view/3984

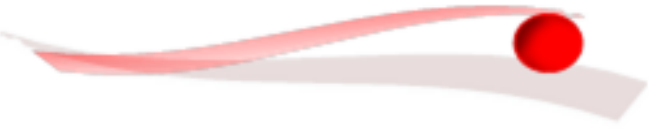

\section{Miftahul Maesaroh}

Indonesia

(3) Universitas Islam Negeri Maulana Malik Ibrahim Malang Indonesia

\section{Corresponding Author}

(C) 085815483192

(9)vrienzha@yahoo.co.id

\section{Miftahul Maesaroh}

Indonesia

\section{كتاب الترجمة بالمدخل البنائي في الدورة \\ التلدربلية العربية}

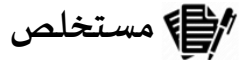

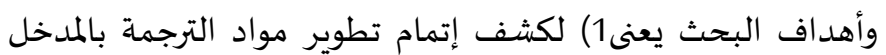

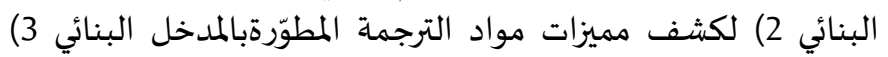

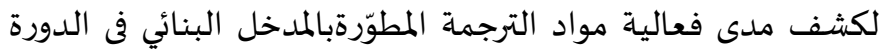

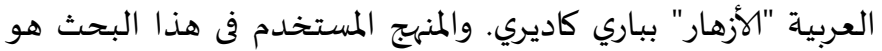

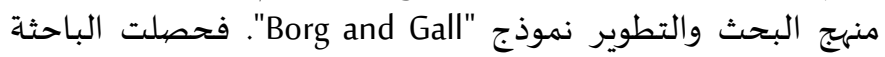

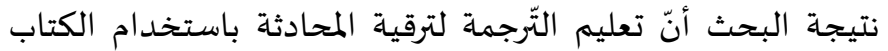

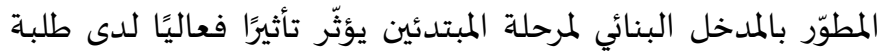

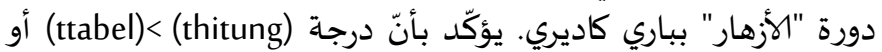

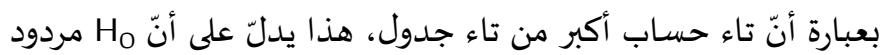
مقبول. ج) نطوير، مواد الترجمة، المدخل البنائي، دورة الأزهار العربية
\end{abstract}

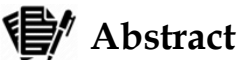

The purpose of the study as follows: 1) to uncover the process of developing teaching materials constructivist approach in translation with Arabic language courses "Al-Azhar" Pare? 2) to reveal the characteristic of teaching materials that have been developed by the constructivist approach in Arabic language courses "Al-Azhar" Pare? 3) to reveal the effectiveness of teaching materials that have been developed by the constructivist approach in Arabic language courses "Al-Azhar" Pare? The method used in this research is "Research and Development" model Borg and Gall. The results of the study of learning by using teaching materials translation of the constructivist approach has the effect for students in Arabic language courses "Al-Azhar" Kediri. These results are corroborated by evidence that the results of the analysis thitung $>\mathrm{t}$ table (thitung bigger than $\mathrm{t}$ table ) shows that $\mathrm{H}_{0}$ rejected and $\mathrm{H}_{\mathrm{a}}$ accepted.

(2) Development, Translation Teaching Material, Constructivist Approach, "Al-Azhar" Course

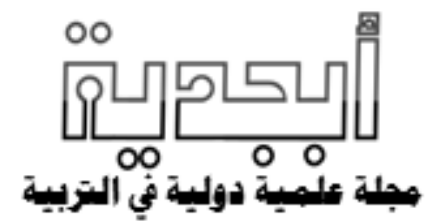




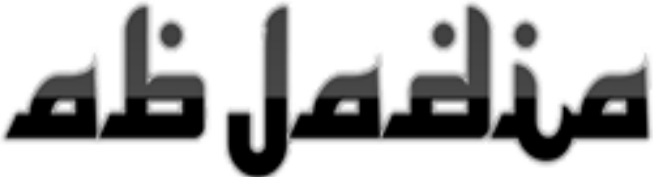 \\ International Journal of Education}

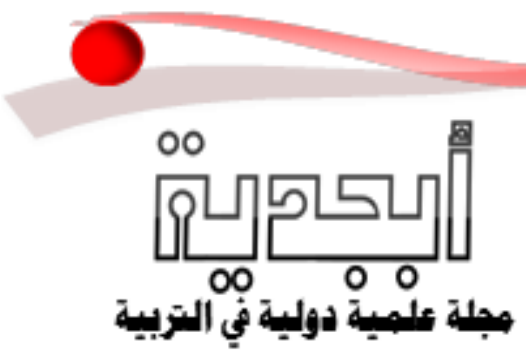

\section{雎" Abstrak}

tujuan penelitian sebagai berikut: 1) untuk menyingkap proses pengembangan materi ajar terjemah dengan pendekatan konstruktivistik di kursus bahasa Arab "Al-Azhar" Pare Kediri? 2) untuk menyingkap karakterisik materi ajar yang telah dikembangkan dengan pendekatan konstruktivistik di kursus bahasa Arab "Al-Azhar" Pare Kediri? 3) untuk menyingkap efektifitas materi ajar yang telah dikembangkan dengan pendekatan konstruktivistik di kursus bahasa Arab "Al-Azhar" Pare Kediri? Metode yang digunakan dalam penelitian ini adalah "Research and Development" model Borg and Gall. Hasil penelitian pembelajaran dengan menggunakan materi ajar terjemah dengan pendekatan konstruktivistik mempunyai pengaruh bagi pelajar di kursus bahasa Arab "AlAzhar" Kediri. Hasil tersebut dikuatkan dengan bukti bahwa hasil analisis thitung $>\mathrm{t}$ table ( $\mathrm{t}$ hitung lebih besar daripada $\mathrm{t}$ table ) menunjukkan bahwa $\mathrm{H}_{0}$ ditolak dan $\mathrm{H}_{a}$ diterima

@ Pendidikan, Mutu, Redireksi, Reevaluasi

http:// ejournal.uin-malang.ac.id/index.php/abjadia/article/view/3984

مقدمة

\section{(C)}

كانت الدورة التدربية العربية "الأزهار" أحد من الدورات التدرببية العربية بباري كاديري جاوى

الشرقية. ركّزت دورة "الأزهار" على تعليم المحادثة في أوّل تأسيسـه بالأسـاس أنّ تعلّم اللغة هو الكلام والتطبيق. وبمرور الزمان وتطوّره لاسيما في هذا العصر الحديث قد بدت طرائق التعليم وأساليبـا ومنهجيتاه وأي مكوّنات الأخرى. تطوّرت هذه الدورة التدربية في فكرته أيضًا بكثرة الطلبة المتنوعاة الذين يتعلّمون فى هذه الدورة التدريبية.

وقبل أن قامت الباحثة بالبحث قد قامت الباحثة بدراسة استقصائية لملاحظة عملية التعليم والتعلّم فيها، والمقابلة بمؤسس الدورة وبعض معلّمها، وتحليل مشكلات الطلبة وإحتياجاتها لهذه الدورة التدربيية. فهذه الدراسة تنتج على أنّ التعليم فى الدورة لا تحتاج الزمان الطويل أو يستغرق وقتا محددا، كما قد جرى في هذه الدورة كانت مدة تعليمه أسبوعين أقلّ. وكان المتعلمون في الدورة من عدة الجوانب والخلفية والسنين لذلك ينبغي على المواد التعليمياة مناسبة لجميع المرحلة وسهلة لفهمها.وكان بعض الطلبة في مرحلة المبتدئين يشعرون بالصعوبة حينما يتعلم اللغة العربية خاصيةً ترجمة اللغة من الإندونيسية إلى العبرية، وهذا الحال يتأثّر إلى مهارة الكلام أو المحادثة.

وهذه الظاهرة أحد من ظواهر اللغة عامة وخاصية في مجال الترجمة. وكذلك ذكر أحمد مختار عمر في كتابه "علم الدلالة" وهو يبحث خاصيًا فى باب واحد عن مشكلة الترجمة ـ أنّ عمليّة الترجمة تظهر عدّة المشكلات بعضها اختلاف سياق لغة المصدر ولغة الهدف،واختلاف القواعد اللغوية، واختلاف 
الثقافة اللغوية وهلم جر. من هذا الأساس يعنى أنّ كلّ مشكلة تحتاج إلى الحلّ إمّا مشكلة لغوية أو تقنيتها.

وبهذه المواد، تستخدم الباحثة المدخل البنائي في تطوير المواد لأن هذا المدخل يرى أن المعرفة يبنيها

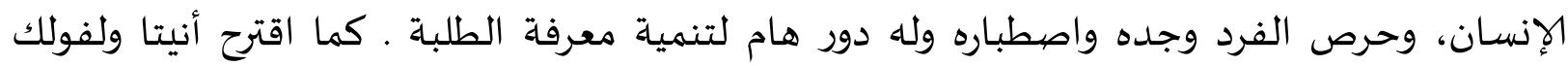
أنّ تعريف المدخل البنائي هو "التعلم الذى يؤكد على دور النشاط الطالب في بناء (Anita Woolfolk) التفاهم وإعطاءالمعنى لمعلومات التى حدثت "وبهذا المدخل يرجى على الطلبة يستطيعون أن يبنوا المعرفة بفكرتهم وينموا فكرتهم النقدية في تعلّم اللغة العربية. أسئلة البحث: (1) كيف يتم تطوير مواد الترجمة بالمدخل البنائي للدورة التدربية العربية بتطبيق فى دورة “الزهار”بباري كاديري؟ (2) ما مميزات مواد الترجمة المطوّرة بالمدخل البنائي للدورة التدريبية العربية بتطبيق فى دورة “ازٔزهار”بباري كاديري؟ (3) ما مدى فعالية مواد الترجمة المطوّرة بالمدخل البنائي

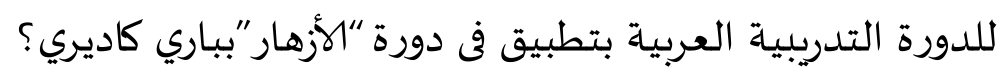
أهداف البحث: (1) كشف عملية تطوير مواد الترجمة بالمدخل البنائي للدورة التدريبية العربية بتطبيق فى دورة “أزهار”بباري كاديري، (2) كشف مميزات مواد الترجمة المطوّرة بالمدخل البنائي للدورة التدريبية العبية بتطبيق فى دورة “أزهمار”بباري كاديري، (3) كشف فعالية مواد الترجمة المطوّرة بالمدخل البنائي للدورة التدرببية العربية بتطبيق في دورة “أزههار ببباري كاديري.

\section{[Q]}

تستخدم الباحثة لهذه الدراسة مدخل البحث والتطوير، مجردًا بأنّ هذا البحث يقصد لأن يطوّر

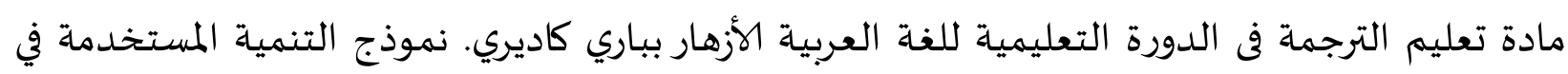
تطوير هذه المواد التعليمية هي نموذج "Borg and Gall"، التي تعد واحدة من منهجية نموذج التصيميم التعليمي. خطوات نموذج التصميم التعليمي وفقا ل"Borg and Gall " النموذج هي على هذه المرحلة: 


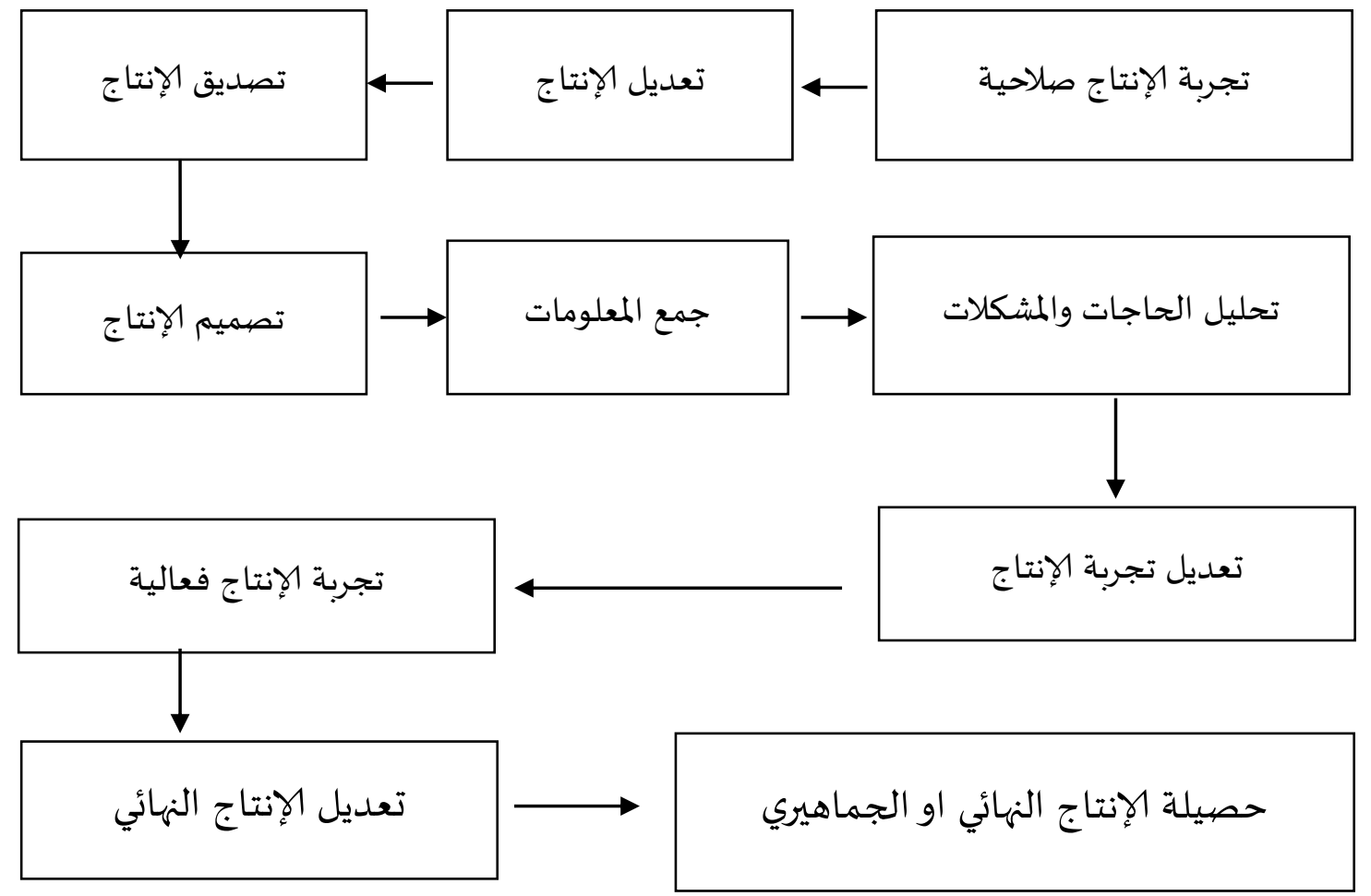

تصميم التجربة يتكون تصميم التجربة بثلاثة مراحل، هي: (1) التقويم والتوجيهات من ثلاثة خبراء تعنى خبير المواد التعليميّة، وخبير تصيميم الكتاب التعليميّ، و خبير اللغة العربية خاصيًا في مجال الترجمة. (2) التجربة الفردية، تقدّم الباحثة إلى مدرّس الترجمة لتصحيح تقصيرات الكتاب قبل التطبيق. (3) التجربة الميدانية، تجرّب الباحثة في الفصل التجريبي لمعرفة فعالية الإنتاج لدى الطلبة. أدوات جمع البيانات التي استخدمتها الباحثة هي: (1) المقابلة، (2) الاستبانة، (3) الاختبار.أما أسلوب تحليل البيانات فيتكون من: (1) تحليل البيانات الوصفية/ الكيفياة، (2) تحليل البيانات الكمّية. تحليل البيانات الوصفية/ الكيفية

أنّ تحليل البيانات الوصفية مستخدمة لتحليل الإحتياجات بعد مقابلة مدرّسة الترجمة وطلبتها بطريقة المقابلة المباشرة ونوعيته الحرّة، وآراء الخبراء عن مضمون الكتاب التعليمي. وخطواتها كما قام ميليس (Miles) وهوبيرمان (Huberman) هي: (1) اختزال البيانات ( Data)

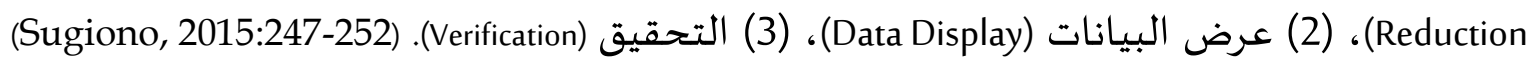
تحليل البيانات الكمّية

(أ) تحليل البيانات من إستبانة تحكيم الخبراء واستجابة الطلبة والمعلّم. وللحصول على البيانات المرجوة تستخدم الباحثة مقياس ليكرت (likert). ويعتمد المقاييس على دليل درجة الوافقة: 


\begin{tabular}{|c|c|}
\hline الإجابة & الدرجة \\
\hline ناقص & 1 \\
\hline مقبول & 2 \\
\hline جيد & 3 \\
\hline جيد جدًا & 4 \\
\hline
\end{tabular}

Hasan, (لمعرفة صحة الإنتاج فلا بد على البيانات أن تبدلها على البيانات الكمية بالرموز التالى $:(2003: 30$

$$
p=\frac{\Sigma x i}{\Sigma x} x 100 \%
$$

(ب) تحليل البيانات من الإختبار

ولمعرفة نجاح الطلبة في تدريس اللغة العربية بالمواد التعليمية على الأساس المدخل البنائي تعتمد الباحثة على معيار الاتقان الأدنى (SKM) في هذه الدورة وهي 60. وتستخدم الباحثة المواصفات للنظم المعياري (Penilaian Acukan Patokan) لمعرفة الدرجة المعدلة، وهي كما يلي:

$$
\text { الجدول } 2
$$

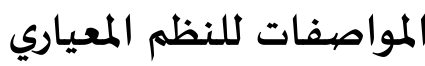

\begin{tabular}{|c|c|c|}
\hline الرقم & الدراوت & 1 \\
\hline ممتاز & $100-91$ & 2 \\
\hline النتيجة & $90-71$ & 3 \\
\hline جيد & $70-61$ & 4 \\
\hline مقبول & $60-51$ & 5 \\
\hline
\end{tabular}

وسوى ذلك، استخدمت الباحثة اختبارت ت (T-test) لقياس الإختبار القبلي والإختبار البعدي بشكل اختبار (ت) المتعلّقة (correlated sample)، و لمعرفة فرق معدل المعاعلة النتيجة بينهما .(Nurgiyantoro, 2009:189-190) 


$$
t=\frac{\Sigma \mathrm{D}}{\sqrt{\frac{\left(\mathrm{N} \Sigma \mathrm{D}^{2}-(\Sigma \mathrm{D})^{2}\right.}{\mathrm{N}-1}}}
$$

تمّت الباحثة تطوير مواد الترجمة بالمدخل البنائي للدورة التدرببية العربية بتطبيق فى دورة الزهار

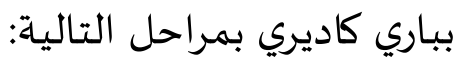
تحليل الحاجات والمشكلات

في هذه المرحلة حلّلت الباحثة بطريقتين هما إقامة المقابلة بمؤسسي الدورة "الزٔهار" ومعلّم الترجمة فيها، وبإعطاء الإستبانة لدي الطلبة. ونتيجة منهما أنّ عمليّة التعليم في هذه الدورة التدريبية تحتاج الكتاب التعليمي للترجمة لمرحلة المبتدئين لترقية المحادثة وأمّا احتياجات الطلبة عن الكتاب هي الكتاب الجذّاب لتشجيع التعلّم، والتدرببات المتنوّعة، والكتاب سهل لفهمه، والكتاب الّذى يدافع الطلبة للتعلّم التناوعيّ، والمادة تتعلّق بالخبرة اليومية، والكتاب فياء الصور

$$
\text { تصيميم الانتاج }
$$

صهمّمت الباحثة كتاب التّرجمة وطوّرته حسب المدخل البنائي من كلّ النواحي تعنى: من جهة كيفية تقديم الكتاب، والموضوعات، وتدريباتها، ومعالجة قواعدها المناسبة لترقية المحادثة لمرحلة المبتدئين. وهي كما يلي:

(أ) صمّمت الباحثة كتاب الترجمة من اللغة الإندونيسية إلى العربية للمبتدئين بالمدخل البنائي بشكل المطبوع الورقي (hardcopy). وحجم الأوراق من الكتاب هو (A4). والأوراق من قرطاس أبيض اللون. وحجم الخط 22 نوع من (Times New Roman) إمّا اللغة الإندونيسية أو العربية. وكلّ من الأوامر أو البيان في هذا الكتاب يستخدم اللّخة الإندونيسيّة، لأنّ الكتاب موجّهـ لطلاب الدورة في المرحلة المبتدئين.

(ب) يحتوى وجـه غلاف الكتاب على موضيوع الكتاب "Menerjemah BahasaArab Cepat dan Mudah"، وفيه إسم المؤلف، وكلمة الشعار، وصيور التلميذ والتلميذة، وصيور بعض المفردات، وكتابة الدورة "الأزهار" بالإندونيسي فى زاوية الأدنى من الغلاف. 


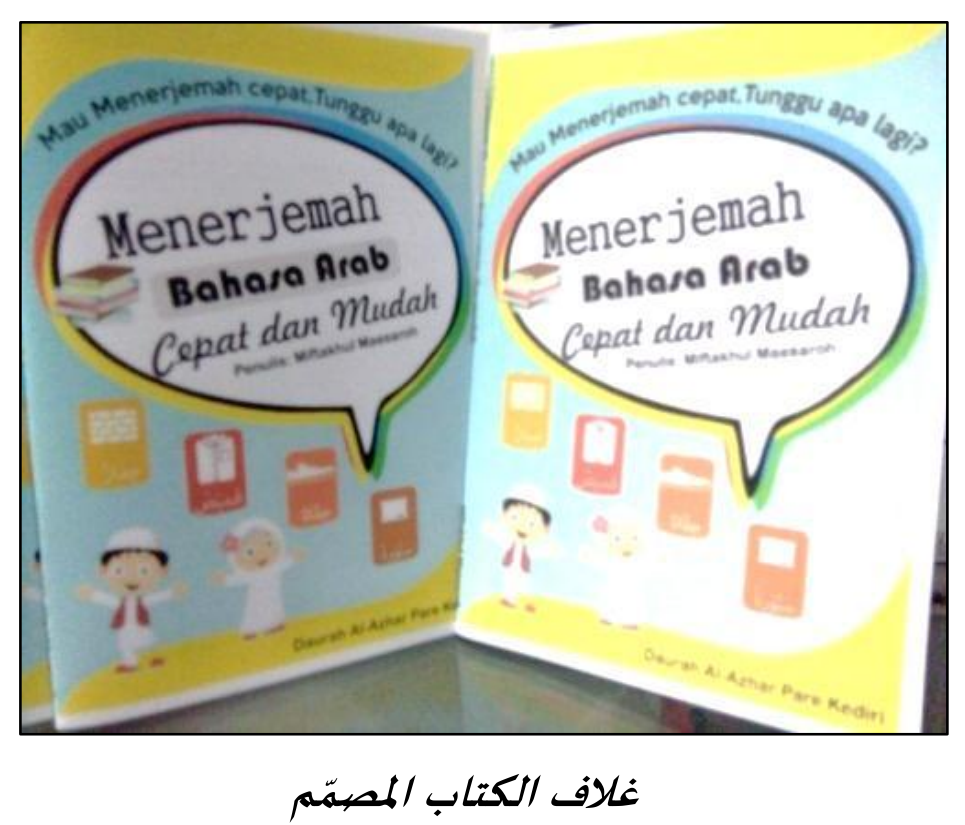

صهمّمت الباحثة الموضوع وكلمة الشعار باللغة الإندونيسية لأنّ يفضّل هذا الكتاب لطلاب الدورة، وكانوا في المرحلة المبتدئين، وهذا الكتاب دليل تعلّم الترجمة من اللغة الإندونيسية إلى اللّغة العربيّة. (ت) كان غلاف كلّ باب عرضته الباحثة كل الدّرس بالموضوع الإندونيسي والعربي والصيورة المعيّنة تتعلّق بالموضوع. الموضوع الإندونيسي أولى وضعته الباحثة هدفًا لتدريب الطلبة عن الترجمة من الإندونيسية إلى العربية وعيًا أو غير وعي، وكذلك لإثراء الطلبة في فهم الأولية عن موضيوع الدّرس.

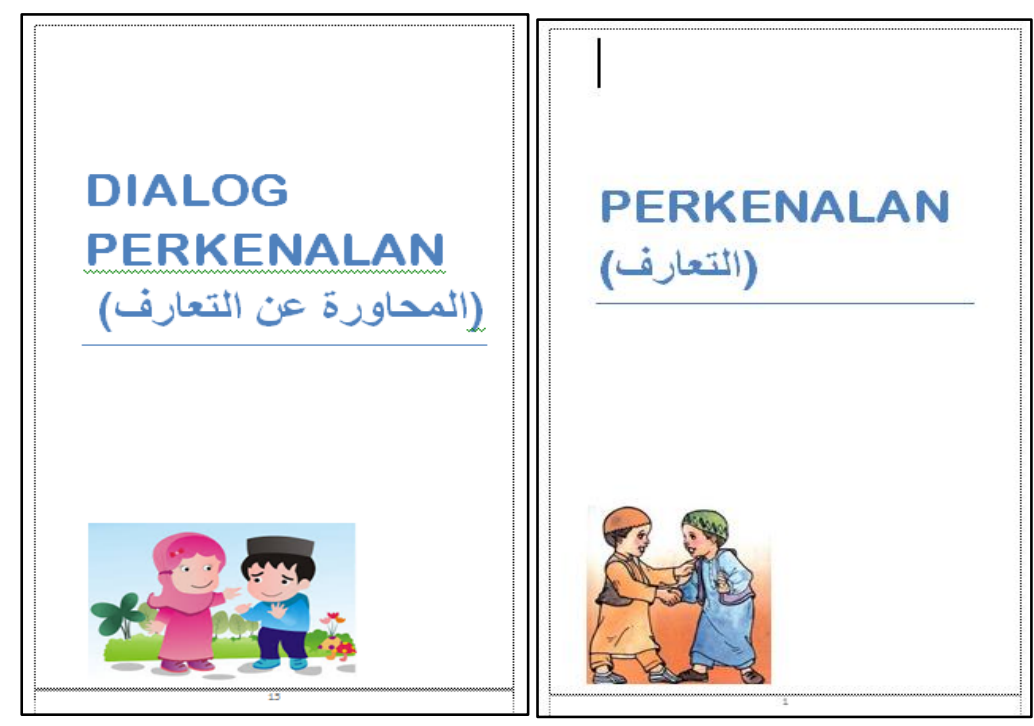

(ث) كان شكل الصفحة الأولى لكلّ باب مشبّها ويتكوّن إلى ثلاثة عناصر يعنى: (1) بدأت الكاتبة بكلمة الإستفهام على الأعلى الورقة، وهذا لا يقصيد بالسؤال لكن الأمر للطلبة لأن يناقشوا أو 
يسألوا عن الإجابة. هذا تقصيد باء الباحثة لتحفيز دماغ الطلبة لأن يتفكّروا، وهذه الطريقة الأسـاسية للمدخل البنائي. (2) وهناك المريّع أو المكان المتنوّعة كمثل وغير ذلك فيه الجملة البسيطة، هذه الجملة ينبنى للطلبة أن يحفّزوا للتفكير "ماهي ترجمة هذه الجملة"، (3) كلمة "ناقشوا بأصبدقائكم" على أدنى الورقة، هذا يقصيد عليهم لأن يناقشـوا ما ترجمة الجملة مع أصيدقائه.
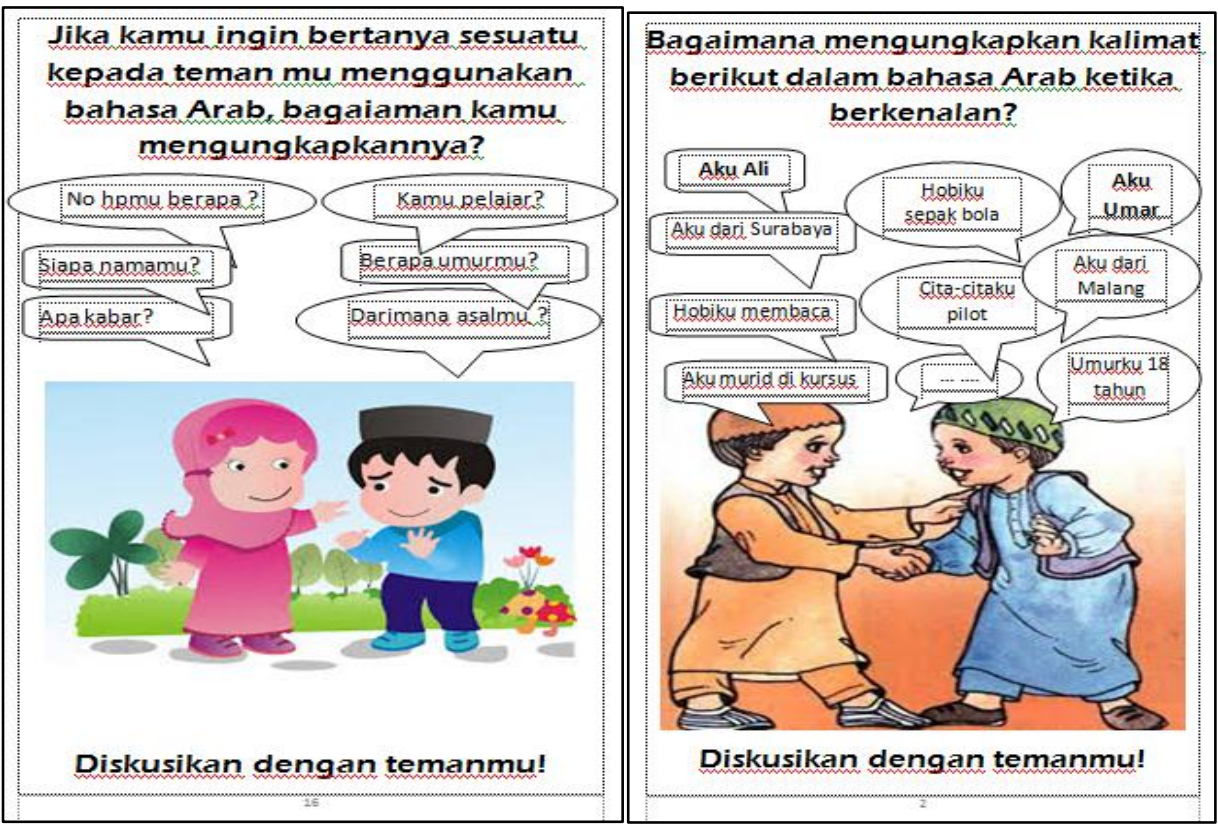

(3) تصيديق الانتاج

قدّمت الباحثة الكتاب المطوّر إلى خبيرين يعنى خبير اللغة والمحتوى وخبير تصيميم المواد. نتيجة الاستبانة من الخبراء الثلاثة

\begin{tabular}{|c|c|c|c|c|c|}
\hline 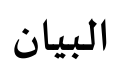 & $\mathbf{P}$ & $X$ & $\mathrm{Xi}$ & 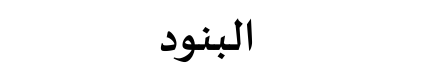 & 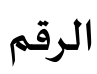 \\
\hline \multirow{2}{*}{ جيّد } & \multirow{2}{*}{$\% 72,85$} & 140 & 102 & د. فيصل فتوي الماجستير & 1 \\
\hline & & \multicolumn{4}{|c|}{ 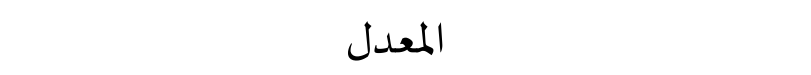 } \\
\hline \multirow{2}{*}{ جيّد } & \multirow{2}{*}{$\% 75,71$} & 140 & 106 & د. توفيق الرحمن الماجستير & 2 \\
\hline & & \multicolumn{4}{|c|}{ المعدل } \\
\hline \multirow{2}{*}{ 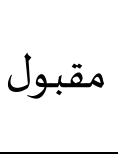 } & \multirow{2}{*}{$\% 67$} & 316 & 201 & د. حليمي زهدي الماجستير & 3 \\
\hline & & \multicolumn{4}{|c|}{ المعدل } \\
\hline \multirow{2}{*}{ جيّد - } & $\% 215,56$ & \multicolumn{4}{|c|}{ المجموع } \\
\hline & $\% 71,85$ & \multicolumn{4}{|c|}{ المعدل العام } \\
\hline
\end{tabular}


فحصلت الباحثة النتائج على درجة "جيّد" فلا بدّ أن يصلحه بالتصحيح البسيط قبل تطبيق

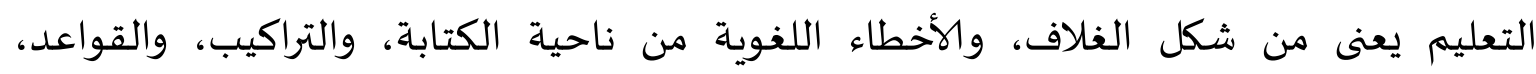

$$
\text { وتصميم الكتاب كي يكون الكتاب جذاباً. }
$$$$
\text { تحسين الانتاج }
$$

أصلحت الباحثة بعض الخطاء الموجودة في الكتاب المطوّر من إقتراحات الخبراءٍ قبل تطبيق التعليم يعنى من شكل الغلاف، والأخطاء اللغوية من ناحية الكتابة، والتراكيب، والقواعد.

$$
\text { (5) }
$$

قامت الباحثة بتجربة صلاحية الانتاج يعنى قدّمت الباحثة اللإستبانة إلى معلّم الترجمة

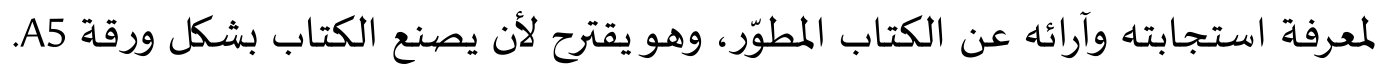

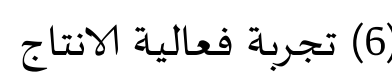

في هذه المرحلة استخدمت الباحثة الكتاب المطوّر لتعليم الطلبة في الفصل، بمراحل الأتية: أخذ نتيجة الإختبار القبلي، والتطبيق الميداني فى الفصل المختار، وأخذ نتيجة الإختبار البعدي، وإعطاء الاستبانة لدى الطلبة لمعرفة استجابتهم عن الكتاب المطوّر، وتحليل فعالية الانتاج. وهذه المرحلة قامت الباحثة بتسع حصات في التطبيق.

$$
\text { (7) حصيلة الإنتاج النهائي او الجماهيري }
$$

وهذه الحصيل الأخير يعنى التصحيح الأخير بعد كلّ المراحل التى قد قامت الباحثة.

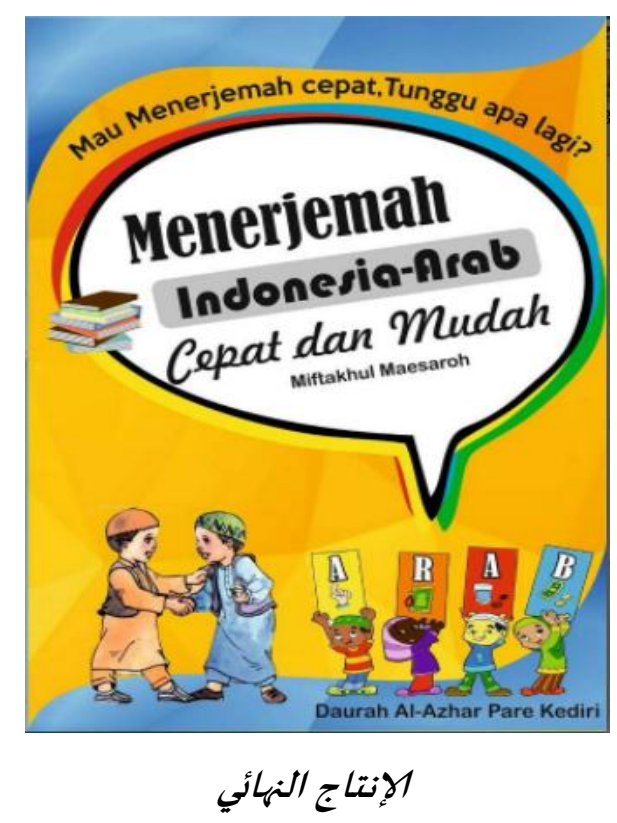


وبعد ما طبّقت الباحثة للتعليم أنّ مواد الترجمة المطوّرة بالمدخل البنائي فى الدورة التدريبية العربية بالتطبيق فى دورة"الأزهار" بباري كاديري يكون فعاليَّا لترقية المحادثة على مرحلة المبتدئين، تؤكد هذا الدليل بأنّ درجة تاء حساب (thitung) في هذا البحث (10,256)، ودرجة تاء جدول بداء (thitung) > (ttabel) على أنّ 19=N - 1 (tabel)

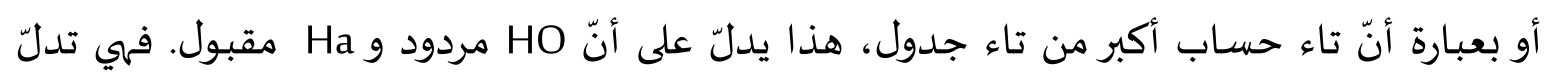

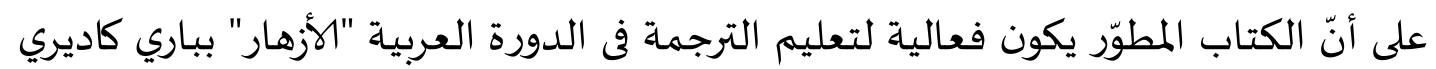

\section{فُبْز مناقشَة}

كان كتاب الترجمة المطوّر يوجّه لطلبة الدورة التدريبية للأمور الأتية نها:كان شكل الكتاب بسيطا، ويستغرق تعليم الكتاب وقتا سريعا في استخدامه، ومن ناحية المحتوى أنّ الكتاب يصمّم على مواد مختصرة ليس ككتاب المدارس فياه البيان الطويل والكثير، وهذه الجوانب ملائمة بطلبة الدورة التدريبية

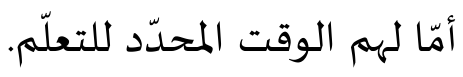

والكتاب المطوّر يوجّه لطلبة مرحلة المبتدئين أينما هم يريدون أن يرتقوا مهارة الكلام أو المحادثة. هذا الكتاب يسمّى بكتاب الترجمة لكن بالهدف لترقية المحادثة لطلبة المبتدئين، لذلك صمّمت الباحثة كتاب الترجمة بأسلوب كيفية صناعة الجملة البسيطة التى تستخدم الموضوعات الشائعة للأعمال اليومية.

وأمّا المدخل المستخدم لتطوير هذا الكتاب هو المدخل البنائي. كما اقترح أنيتا ولفولك ( Anita (Woolfolk

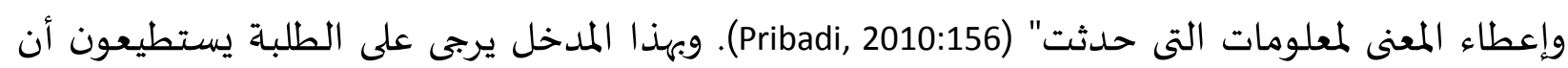
يبنوا المعرفة بفكرتهم وينموا فكرتهم النقدية في تعلّم اللغة العربية. وخصائص هذا المدخل الذى قد استخدمته الباحثة لتطوير هذا الكتاب مثلاً استخدام الجملة

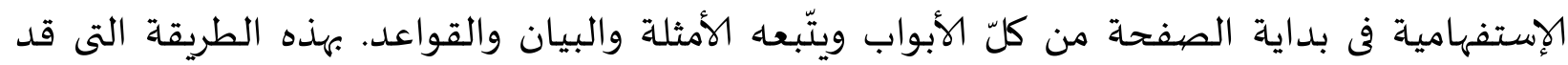
طبّقتها الباحثة بالتجربة الميدانية، سيحصل الطلبة إلى الفكرة النقدية في أثناء التعلّم ويؤدّي إلى كثرة السؤال. وهذه القيمة الأساسية من المدخل البنائي. وهذه أسلوب صناعة الكتاب المطوّر نسبته الباحثة من رأي بعض شيعة (penganut) البنائية للتعلّم وهي كما يلي: 
(2) دور المعلمين في المدخل البنائي لم يعدوا أن يتصرفوا كما يستعد شخص لتقديم عرض المعرفة في وسط الفصل، ولكن بتصميم وإنشاء المواقف والخبرات التعليمية لمساعدة الشباب على إعطاء معنى لمفهوم العلم المدروس (Pribadi, 2010:156).

والغرض من التعلم يعنى التعلم كيفية التعلم (how to learn). أي أن يكون الطلاب لديهم القدرة

على العثور عليها، فهم واستخدام المعلومات والمعرفة المكتسبة

(4) استراتيجية التعلم في وجهة النظر البنائية في التعلم الذي هو أكثر الموجهة لخدمة سؤال أو عرض موضوع الدراسة. أكثر من ذلك التركيز على مهارات التفكير النقدي مثل التحليل والمقارنة، والتعميم،

وتوقع، وافتراض. (Machmudah, 2008:35).

(5) آثار البنائية في عملية التعلم هي عملية بناء المعرفة من تجريد كل التجربة الطبيعية والبشرية (6) الآثار المترتبة على عملية التدريس البنائية هي أن التعليم هو العملية التي تساعد الشخص على تشكيل معرفته (Machmudah, 2008:35).

\section{خاتمة}

إن عملية تطوير مواد الترجمة بالمدخل البنائي للدورة التدرببية العربية بتطبيق في دورة “أزهار”بباري كاديري تجري على سبعة مراحل، وهي: (1) تحليل الحاجات والمشكلات، (2) تصميم الانتاج، (3) تصديق الانتاج، (4) تحسين الانتاج، (5) تجربة صلاحية الانتاج، (6) تجربة فعالية الانتاج، (7) حصيلة الإنتاج الههائي او الجماهيري.

أما مميزات مواد الترجمة المطوّرة بالمدخل البنائي للدورة التدرببية العربية بتطبيق فى دورة “أزهار”بباري كاديري فهي: (1) إن المعرفة غير موضوعية،، وتغيير دائما وغير مؤكد؛ (2) دور المعلمين في المدخل البنائي لم يعدوا أن يتصرفوا كما يستعد شخص لتقديم عرض المعرفة في وسط الفصل، ولكن بتصيميم وإنشاء المواقف والخبرات التعليمية لمساعدة الشباب على إعطاء معنى لمفهوم العلم المدروس؛ (3) والغرض من التعلم يعنى التعلم كيفية التعلم (how to learn). أي أن يكون الطلاب لديهم القدرة على العثور عليها، فهم واستخدام المعلومات والمعرفة المكتسبة؛ (4) استراتيجية التعلم في وجهة النظر البنائية في التعلم الذي هو أكثر الموجهة لخدمة سؤال أو عرض موضوع الدراسـة. أكثر من ذلك التركيز على مهارات التفكير النقدي مثل التحليل والمقارنة، والتعميم، وتوقع، وافتراض؛ (5) آثار البنائية في عملية التعلم هي 
عملية بناء المعرفة من تجريد كل التجربة الطبيعية والبشرية؛؛ (6) الآثار المترتبة على عملية التدريس البنائية هي أن التعليم هو العملية التي تساعد الشخص على تشكيل معرفته.

فعالية مواد الترجمة المطوّرة بالمدخل البنائي للدورة التدربيية العربية بتطبيق فى دورة “أزهار”بباري كاديري تبدو من تعليم التّرجمة لترقية المحادثة باستخدام الكتاب المطوّر بالمدخل البنائي ttabel)> (لمرحلة المبتدئين يؤثّر تأثيرًا فعاليًا لدى طلبة دورة "الزٔهار" بباري كاديري. يؤكّد بأنّ درجة (thitung) أو بعبارة أنّ تاء حسـاب أكبر من تاء جدول، هذا يدلّ على أنّ HO مردود و Haمقبول.

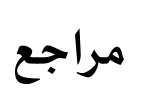

Suparno, Paul. 1997. Filsafat Konstruktivisme dalam Pendidikan. Yogyakarta: Kanisius.

Pribadi, Benny A. 2010. Model Desain Sistem Pembelajaran. Jakarta: Dian Rakyat

Arikunto, Suharsimi. 2007. Dasar-Dasar Evaluasi Pendidikan. Jakarta: PT. Bumi Aksara

Sugiyono. 2015. Metode Penelitian Pendidikan Pendekatan Kuantitatif, Kualitatif dan RED. Bandung: Alfabeta

Hasan, Iqbal. 2003. Analisis Data Penelitian dengan Statistik. Jakarta: PT Bumi Aksara.

Nurgiyantoro, Burhan. 2009. Statistik Terapan untuk Penelitian Ilmu-Ilmu Sosial. Cet. Ke-4. Yogyakarta: Gadjah Mada University Press

Machmudah, Umi \& Rosyidi, Abdul Wahab. 2008. Active Learning Dalam Pembelajaran Bahasa Arab. Malang: UIN Press.

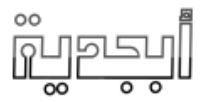

